\title{
The Correlation Between Gross Domestic Product Per Capita and the Success Rate of Assisted Reproductive Technologies Worldwide
}

\author{
Jie Dong ${ }^{1}$, Song Yan ${ }^{1}$, Chenxi Qian ${ }^{1}$, Xiaohong Wang ${ }^{1}$ \\ ${ }^{1}$ Reproductive Medical Center, Department of Obstetrics and Gynecology, Tangdu Hospital, Air Force Medical \\ University, Xi'an, Shaanxi Province, China
}

\begin{abstract}
Objective: Although there has been increased utilization of assisted reproductive technologies (ART) in the world, there is no conclusive definition about the relationship between the success rate of ART and national wealth.

Methods: In this study, using the data from the International Committee for Monitoring Assisted Reproductive Technologies (ICMART), we sought to determine whether there is a correlation between the success rate of ART (represented by pregnancy and delivery rates) and national wealth represented by the gross domestic product (GDP) per capita. Moreover, to further understand the effect of GDP per capita on ART effectiveness, we analyzed the association between ART success rate and GDP per capita in 50 US states.

Results: Our data showed that the number of ART treatment cycles increased as the GDP per capita increased. However, we found a negative correlation between ART success rates and GDP per capita in ICMART countries, although no correlation was seen in the US states. Using rough estimation, we derived that the success rate of ART was not related to GDP per capita in the ICMART countries with a GDP per capita greater than USD 13,000.

Conclusions: In conclusion, for the first time, we showed that when the GDP per capita of an economic territory reaches (or exceeds) USD 13,000, ART pregnancy and delivery rates were not associated with GDP per capita, and ART success rates remained stable.
\end{abstract}

Keywords: GDP, assisted reproductive technologies, pregnancy rate, delivery rate

\section{INTRODUCTION}

Since the world's first "test-tube" baby was born in 1978, assisted reproductive technologies (ART) have developed rapidly and been widely used all over the world. Commonly used ART includes in vitro fertilization (IVF), intracytoplasmic sperm injection (ICSI), and frozen embryo transfer (FET). It has been reported that over eight million babies have been born via ART (European Society of Human Reproduction and Embryology, 2018). Today, in some countries, ART-conceived infants account for between $1.8 \%$ to $5 \%$ of all infants (Sunderam et al., 2019; European IVF-monitoring Consortium (EIM) $\neq$ for the European Society of Human Reproduction and Embryology, 2020). However, despite the advances in ART, its success rate per treatment cycle remains low. Based on the ART data of 69 countries, the ICMART has reported that the delivery rate via IVF/ICSI (combined) and FET is $19.8 \%$ and $22.1 \%$, respectively (de Mouzon et al., 2020). In the United States, official data shows that the live birth rate per cycle via IVF/
ICSI (combined) and FET for non-donor women aged less than 35 years is $31.0 \%$ and $49.4 \%$, respectively; and the rate gets lower for older women (Sunderam et al., 2019).

Multiple factors have been associated with the low percentages of live births, including parent age, infertility-related factors, and ART manipulation itself (Tarín et al., 2014). The quality and policies of a healthcare system may also influence ART success rates. For example, a superior healthcare system that is funded properly could mean better ART services. Commonly, developed countries/regions provide superior healthcare systems and funds to support ART treatments to infertile couples. Hence, ART treatments in these countries/regions are relatively affordable, especially to sub-fertile couples, and may achieve a high success rate. Surprisingly, a study performed by Lass et al. (2019) refutes this postulation. Although the study found a robust positive correlation between the number of IVF cycles performed and GDP per capita, it also showed that both pregnancy and delivery rates via IVF were inversely correlated with the GDP per capita. The researchers assumed that the unexpected findings were associated with inadequate comprehensive data collection (such as age distribution, causes of infertility, and quality control level of embryo handling - due to objective limitations). Based on their limited data, however, it appears that developed countries do not have a high IVF success rate.

Despite the gradual increase in the usage of other regular ART treatments (such as ICSI and FET) (European IVF-monitoring Consortium (EIM) $\neq$ for the European Society of Human Reproduction and Embryology, 2020), there has been no conclusive answer about the relationship between the success rate of ICSI/FET cycles and national wealth. Therefore, using data from the ICMART, we investigated whether there is a correlation between pregnancy/ delivery rates from ICSI/FET cycles and national wealth represented by the GDP per capita. Moreover, to increase the understanding of the effect of national wealth on the effectiveness of ART, we analyzed the relationship between ART success rate and GDP per capita in 50 states of the US.

\section{MATERIALS AND METHODS}

All original data analyzed were collected from published papers and materials. We used the latest ICMART ART data (including treatment cycles, pregnancy, and delivery rates) (de Mouzon et al., 2020) and the GDP per capita data of all countries in the world in 2012. Given the potential influence of confounding factors, such as demographic and cultural characteristics, we increased our scope to analyze ART data from 50 US states. To maintain consistency with the 2012 ICMART data, we collected the 2012 ART data of individual states released by the US Health Department in 2015 (Sunderam et al., 2015), and the 2012 GDP per capita of each state (Brooks et al., 2013). The original data are populated in the Supplementary Tables 1 and 2 . 


\section{Statistical Analyses}

Data analyses were performed using IBM SPSS Statistics 23.0 (IBM software, 81 NY, USA). Graphics were drawn using Prism 8 (GraphPad Software, CA, USA). Normal variables are shown as means and standard deviation, and non-normal variables are shown as medians with percentile values. We used Spearman's rank correlation coefficient to investigate the relationship between GDP per capita (unit: 10 thousand dollars) and ART cycles, and employed Pearson's correlation coefficient (CC) to investigate the relationship between GDP per capita and ART success rate after logarithmic processing of GDP per capita (shown as LogGDP). A $p$-value $<0.05$ (two-tailed) was considered significant.

\section{RESULTS}

1. The number of ART treatment cycles increased as the GDP per capita increased based on 2012 ICMART data.

Considering the different ARTs corresponding to different applicable conditions, we analyzed the correlation between the GDP per capita and the number of cycles of IVF, ICSI, and FET, respectively. Based on ICMART data, we calculated the median of GDP per capita to be 1.53 (0.74-4.36), and the median of the number of cycles of IVF, ICSI, and FET cycles to be 920.0 (277.3-3356.5), 2529.0 (631.5-8988.3), and 713.5 (118.8-5117.0), respectively. As shown in Figure 1, there was a significant positive correlation between GDP per capita and the number of ART cycles in its various forms, including IVF (Figure $1 \mathrm{a}, \mathrm{CC}=0.695, p<0.001$ ), ICSI (Figure $1 \mathrm{~b}, \mathrm{CC}=0.644$, $p<0.001$ ), and FET (Figure 1c, CC $=0.666, p<0.001$ ). The results suggest that ART treatment cycles increase with an increase in the GDP per capita of a country.

2. The pregnancy and delivery rates both in IVF and ICSI aspiration cycles were negatively correlated with GDP per capita based on 2012 ICMART data.

Next, we tested the correlation between pregnancy and delivery rates in the three regular ART cycles (IVF, ICSI, and FET) and LogGDP using Pearson's correlation coefficient. The results showed that in IVF cycles, both pregnancy (Figure 2a, CC=-0.263, $p=0.041$ ) and delivery rates (Figure $2 b, C C=-0.329, p=0.012$ ) were inversely correlated with LogGDP of ICMART countries. Similarly, for ICSI cycles, there was a significant negative correlation between pregnancy (Figure $2 \mathrm{C}, \mathrm{CC}=-0.394, p=0.001$ ) and delivery rates (Figure $2 d, C C=-0.417, p=0.001$ ) and logGDP. However, in FET cycles, we found no significant correlation between pregnancy (Figure $2 \mathrm{e}, \mathrm{CC}=-0.006, p=0.961$ ) and delivery rates (Figure $2 \mathrm{f}, \mathrm{CC}=-0.059, p=0.565$ ) and LogGDP. The data herein indicate that the success rate in
IVF and ICSI cycles declines with an increase in the GDP per capita of a country.

3. There was no correlation between ART success rate and GDP per capita based on the 2012 ART data of the 50 US states.

Considering the potential influence of complex demographic, geographical, and cultural backgrounds and their effects on the correlation between GDP per capita and ART success rate, we used data from 50 US states with relatively fewer confounding factors to analyze the relationship between GDP per capita and ART success rate. First, we found that the average pregnancy and delivery rates were $41.6 \pm 5.9 \%$ and $34.2 \pm 5.4 \%$ in ART cycles, respectively. Subsequently, we analyzed the correlation between ART cycles (excluding FET cycles) and GDP per capita, and the results showed that ART procedures increased with an increase in GDP per capita (Figure 3a, CC $=0.298, p=0.036$ ). However, we found that there was no significant relationship between pregnancy (Figure $3 b, C C=-0.019, p=0.896$ ) and delivery rates (Figure $3 c, C C=-0.078, p=0.591$ ) and LogGDP.

4. There may be a boundary point to link the correlation between ART success rate and GDP per capita.

Based on the analysis of 2012 ICMART data and 2012 ART data of 50 US states, we found that there was a negative link between ART success rate and GDP per capita in ICMART countries, although no such correlation was found in the US states. Because the median GDP per capita of the US states [5.38 (4.54-6.15)] in 2012 was much higher than that of ICMART countries [1.53 (0.74-136 4.36)], we speculated that ART success rate might have nothing to do with GDP per capita after the GDP per capita of an economic territory reaches a certain level. In other words, there might be a correlation between ART success rate and GDP per capita within a certain GDP per capita range in ICMART members. To estimate the boundary point, we compared the correlative variables at different GDP per capita levels in determining the association between the ART success rate and GDP per capita. As shown in Table 1, when the GDP per capita was set at $\geq$ USD 12,000 , we found a significant negative correlation between pregnancy rate only in IVF cycles and GDP per capita $(C C=-0.380, p=0.026)$; however, when the GDP per capita was above USD 13,000, there was no statistically significant correlation between pregnancy/delivery rates from IVF and ICSI cycles and GDP per capita. The results indicated that there might be no correlation between ART success rate and GDP per capita when the GDP per capita of an economic territory is greater than USD 13,000 .
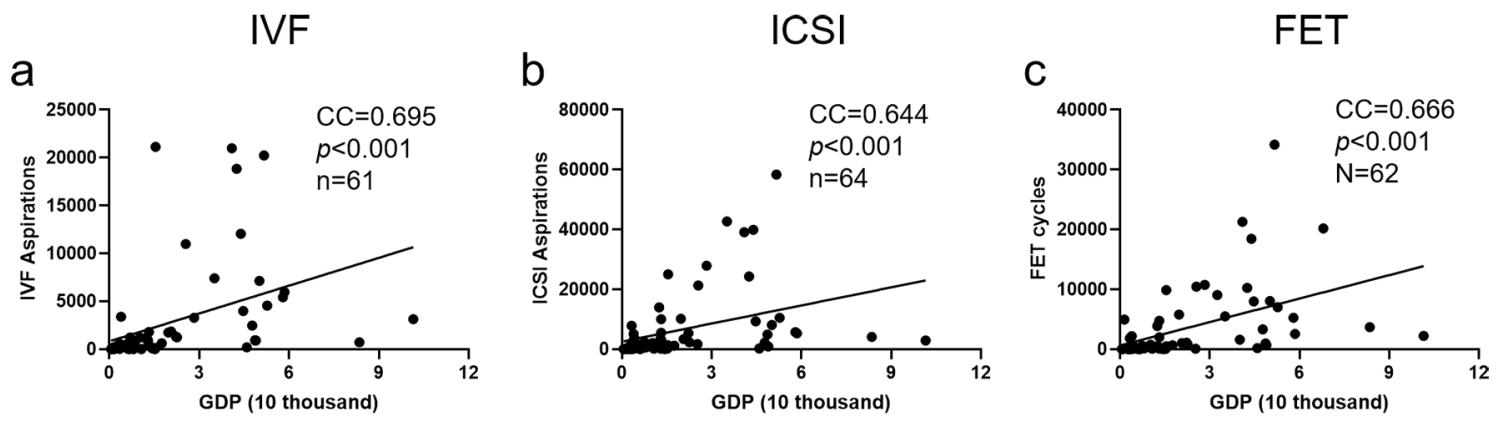

Figure 1. The correlation between GDP per capita (USD 10,000) and number of ART treatment cycles from 2012 ICMART data. a: correlation between GDP per capita and IVF cycles; b: correlation between GDP per capita and ICSI cycles; c: correlation between GDP per capita and FET cycles. CC: correlation coefficient. 

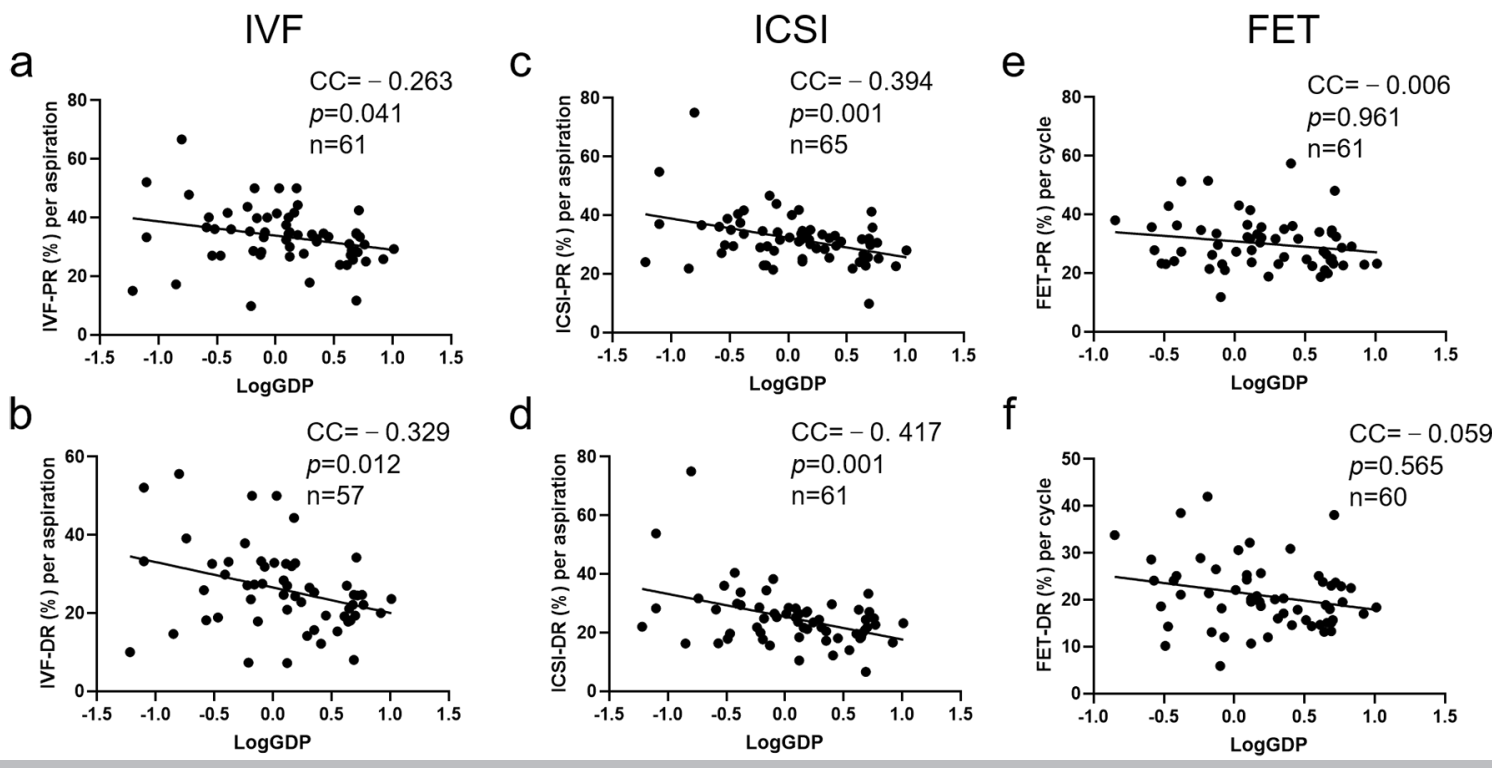

Figure 2. The correlation between LogGDP and pregnancy/delivery rates in ART cycles from 2012 ICMART data, respectively. a: pregnancy rate in IVF cycles (IVF-PR). b: delivery rate in IVF cycles (IVF-DR); c: pregnancy rate in ICSI cycles (ICSI-PR). d: delivery rate in ICSI cycles (ICSI-DR); e: pregnancy rate in FET cycles (FET-PR). f: delivery rate in FET cycles (FET-DR). CC: correlation coefficient.

a

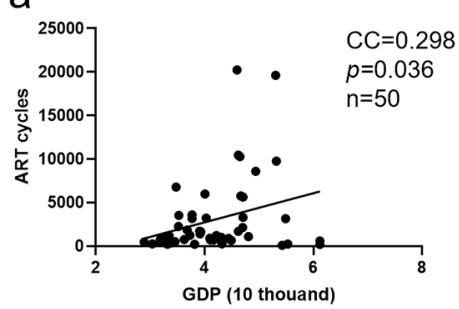

b

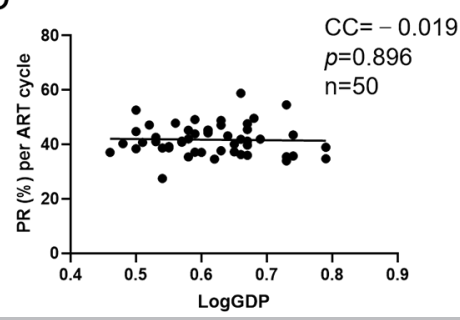

C

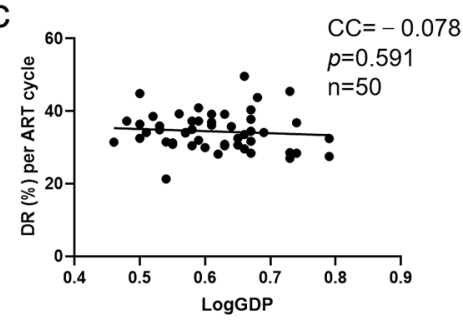

Figure 3. The correlation between GDP per capita and number of ART treatment cycles from 2012 USA data (a). The correlation between LogGDP and pregnancy rate (b) and delivery rate (c) in ART cycles, respectively. CC: correlation coefficient.

\begin{tabular}{|c|c|c|c|c|c|c|}
\hline \multicolumn{3}{|c|}{$\begin{array}{l}\text { GDP per capita } \geq 1.2 \\
(\text { LogGDP } \geq 0.08)\end{array}$} & \multicolumn{4}{|c|}{$\begin{array}{c}\text { GDP per capita } \geq 1.3 \\
(\text { LogGDP } \geq 0.11)\end{array}$} \\
\hline & CC & $p$ value & & CC & $\begin{array}{c}\text { Mean } \\
\text { (deviation) }\end{array}$ & $p$ value \\
\hline $\begin{array}{l}\text { IVF-PR } \\
\mathrm{n}=34\end{array}$ & -0.380 & 0.026 & $\begin{array}{c}\text { IVF-PR } \\
\mathrm{n}=31\end{array}$ & -0.320 & $31.7 \pm 6.85$ & 0.079 \\
\hline $\begin{array}{l}\text { IVF-DR } \\
\mathrm{n}=32\end{array}$ & -0.225 & 0.216 & $\begin{array}{c}\text { IVF-DR } \\
\mathrm{n}=30\end{array}$ & -0.133 & $23.0 \pm 7.4$ & 0.483 \\
\hline $\begin{array}{l}\text { ICSI-PR } \\
n=35\end{array}$ & -0.291 & 0.089 & $\begin{array}{c}\text { ICSI-PR } \\
\mathrm{n}=32\end{array}$ & -0.205 & $29.3 \pm 4.6$ & 0.260 \\
\hline $\begin{array}{l}\text { ICSI-DR } \\
\mathrm{n}=33\end{array}$ & -0.090 & 0.620 & $\begin{array}{c}\text { ICSI-DR } \\
\mathrm{n}=31\end{array}$ & 0.039 & $21.5 \pm 4.9$ & 0.834 \\
\hline
\end{tabular}

\section{DISCUSSION}

In this study, we investigated the correlation between the ART success rate of a country (represented by pregnancy and delivery rates) and its wealth (represented by the GDP per capita). Relying on data from 2012 ICMART members and 50 US states, we found different results: there was a negative correlation between ART success rate and GDP per capita in ICMART countries, but no such correlation existed in the 50 US states. Using rough estimation, we found that ART success rate was not related to GDP per capita in ICMART countries when the GDP per capita was greater than USD 13,000. Therefore, we 
conclude that when the GDP per capita of a country or economic territory exceeds USD 13,000, their ART pregnancy and delivery rates might remain at a stable level.

An estimated more than 48 million people are affected by infertility worldwide (Mascarenhas et al., 2012). Many IVF clinics are opening across the world to help infertile couples have babies. Data from the IVF-Worldwide website (www.ivf-worldwide.com) show that more than 3,000 IVF clinics are operational, but ART treatments are still inadequate in many parts of the world, particularly in developing countries (Inhorn \& Patrizio, 2015).

However, the prevalence of infertility worldwide is comparable across low-, middle-, and high-income countries (Asemota \& Klatsky, 2015). Accordingly, wealthier countries show more utilization of ART treatments. According to our data, there is a higher ART utilization rate (including IVF, ICSI, and FET cycles) in countries/regions with a higher GDP per capita. In their study, Lass et al. (2019) also showed a positive correlation between the utilization rate of IVF and the GDP per capita of countries/regions. This can be attributed to the affordability of receiving ART treatments in these countries/regions. As such, governments across the world should begin and/or continue/ increase support for ART treatments, as occurs in Nordic countries (Lass et al., 2019).

Generally, people expect developed countries/regions to have high success rates of ART treatments. However, data from ICMART member countries showed a strong negative correlation between GDP per capita and IVF/ICSI treatment success rates in developed countries/regions. Noticeably, countries with a lower GDP per capita had higher pregnancy and delivery rates in IVF/ICSI treatments. It is difficult to determine the cause of this startling relationship owing the limitations of data availability. A few potential factors may explain this relationship. For example, it is well known that female age is remarkably associated with fertility and ART success rate; women aged over 35 years have reduced fecundity and, therefore, lower pregnancy rates especially via ART treatments (Howles et al., 2006). Evidence shows that, in developed countries, women prefer to have children late in their lives (Mills et al., 2011). To allow time to finish their education, pursue careers, or attain financial independence, many women in developed countries delay starting families until they are 40 years or older (Mills et al., 2011; Armstrong \& Akande, 2013). This phenomenon means that reproductive health clinics are treating a higher number of older infertile women with more complicated gynecological conditions, such as diminished ovarian reserve, endometriosis, and adenomyosis, thereby, the reduced ART success rate in these countries. In Japan, for example, a country with a serious aging problem (Nishi et al., 2020), the pregnancy and delivery rates are much lower even by IVF $(11.7 \%$ and $8 \%$, respectively) and ICSI $(9.8 \%$ and $6.6 \%$, respectively) (Supplementary Table 1). Another factor affecting the ART success rate may be the number of treatment cycles. As our data show, the ART treatment cycles grow as the GDP per capita of an economic territory increases. Statistically, the success rate of ART treatments calculated from a larger number of cases should be closer to the overall rate. Thus, the pregnancy and delivery rates in IVF/ICSI cycles in low-income countries (such as Ghana, Mali, and Nicaragua) might not adequately reflect their ART success rate owing to the relatively small number of IVF/ICSI cycles.

Additionally, the different cultural backgrounds across regions may affect the correlation between GDP per capita and ART success rate. However, it is difficult to test and verify their role in ART success rate owing to data unavailability. Therefore, to reduce the influence of cultural backgrounds, we used data from 50 US states with relatively lower confounding factors to analyze the relationship between GDP per capita and ART success rates. Surprisingly, we found no significant correlation between GDP per capita and ART pregnancy/delivery rates based on the US CDC data. Given the high GDP per capita of the US states, we hypothesized that ART success rates might have nothing to do with GDP per capita when the GDP per capita of an economic territory reaches a certain level. Subsequently, by analyzing data of ICMART members, we estimated this GDP per capita threshold to be USD 13,000; in other words, ART pregnancy and delivery rates were more stable $(20 \%-30 \%$, Table 1$)$ in the regions where the GDP per capita was greater than USD 13,000. Notably, however, the success rate of ART is still not satisfactory worldwide. The latest data from the European Society of Human Reproduction and Embryology (ESHRE) show that the live birth rate per aspiration is $\sim 20 \%$ in both IVF and ICSI cycles (European IVF-monitoring Consortium (EIM) $\neq$ for the European Society of Human Reproduction and Embryology, 2020). It appears that the era of improving ART success rate is moving into a bottleneck period as ART has been developing for 40 years.

This study presents limitations about the quality of data due to the lack of basic characteristics, such as the age distribution of patients, infertility factors, and the quality control standards of reproductive health clinics. It was difficult to collect such detailed information owing to inaccessibility to the reporting registry system. Moreover, only about a third of the countries in the world publish their ART data to ICMART. Currently, a large number of reproductive health clinics are opening in Asian countries, such as China, Thailand, and Vietnam. It will be crucial to obtain ART registry data from these countries. Additionally, owing to the limited ICMART data from a rather small number of countries, we were not able to obtain a fitting curve to show the correlation between GDP per capita and ART success rate (data not shown). We provided only a rough estimate ( USD 13,000) of the boundary point. Therefore, there is a possible bias in obtaining this critical value.

In summary, our study, for the first time, revealed that the success rate of ART might attain a stable level when the national or regional wealth reaches a certain level (GDP per capita of USD 13,000). Despite the low number of ART treatment cycles in developing countries, the ART success rate of these countries is not inferior to that of developed countries. Nevertheless, further studies analyzing more ART data collected from more countries across the world are necessary to understand the influence of socioeconomic status on the overall effectiveness rate of ART treatment.

\section{ABBREVIATIONS}

ART: Assisted Reproductive Technologies

CC: Correlation Coefficient

FET: Frozen Embryo Transfer

GDP: Gross Domestic Product

ICSI: Intracytoplasmic Sperm Injection

ICMART: International Committee for Monitoring Assisted Reproductive Technologies

IVF: In Vitro Fertilization (IVF)

\section{ACKNOWLEDGMENTS AND FUNDING}

We thank the funding provided by Platform construction Funding of Tangdu Reproductive Medicine Center (2020XKPT003).

We would like to thank Editage (www.editage.cn) for English language editing.

\section{Authors' Contributions}

J.D. was involved in study design development, data analysis and manuscript writing. Y. S. participated in data 
collection. C. Q. performed the statistical analysis. X. W. participated in the study design and helped to edit the manuscript. All authors read and approved the final manuscript.

\section{Author Declarations}

The manuscript has been read and approved by all named authors. Approval from an Ethics Committee is not applicable since all data were collected from online publicly available information sources shown in the supplementary file.

\section{CONFLICT OF INTEREST}

The authors have no conflict of interest to declare.

\section{Corresponding author:}

Xiaohong Wang

Reproductive Medical Center,

Department of Obstetrics and Gynecology,

Tangdu Hospital, Air Force Medical University,

Xi'an, Shaanxi Province, China

E-mail: wangxh919@fmmu.edu.cn

\section{REFERENCES}

Armstrong S, Akande V. What is the best treatment option for infertile women aged 40 and over? J Assist Reprod Genet. 2013;30:667-71. PMID: 23536151 DOI: 10.1007/ s10815-013-9980-6

Asemota OA, Klatsky P. Access to infertility care in the developing world: the family promotion gap. Semin Reprod Med. 2015;33:17-22. PMID: 25565507 DOI: 10.1055/s0034-1395274

Brooks LR, Cao LX, Rodriguez RM. Gross Domestic Product by State. Advance Statistics for 2012 and Revised Statistics for 2009-2011. Survey of Current Business; 2013. Available at: https://apps.bea.gov/scb/pdf/2013/07\%20 July/0713_gdp_by_state.pdf

de Mouzon J, Chambers GM, Zegers-Hochschild F, Mansour R, Ishihara O, Banker M, Dyer S, Kupka M, Adamson GD. International Committee for Monitoring Assisted Reproductive Technologies world report: assisted reproductive technology 2012†. Hum Reprod. 2020;35:190013. PMID: 32699900 DOI: 10.1093/humrep/deaa090

European IVF-monitoring Consortium (EIM) $\neq$ for the European Society of Human Reproduction and Embryology (ESHRE), Wyns C, Bergh C, Calhaz-Jorge C, De Geyter C, Kupka MS, Motrenko T, Rugescu I, Smeenk J, Tandler-Schneider A, Vidakovic S, Goossens V. ART in Europe, 2016: results generated from European registries by ESHRE. Hum Reprod Open. 2020;2020: hoaa032. PMID: 32760812 DOI: $10.1093 /$ hropen/hoaa038

European Society of Human Reproduction and Embryology. More than 8 million babies born from IVF since the world's first in 1978: European IVF pregnancy rates now steady at around 36 percent, according to ESHRE monitoring. ScienceDaily; 2018. Available at: https://www.sciencedaily. com/releases/2018/07/180703084127.htm
Howles CM, Kim CH, Elder K. Treatment strategies in assisted reproduction for women of advanced maternal age. Int Surg. 2006;91:S37-54. PMID: 17436604

Inhorn MC, Patrizio P. Infertility around the globe: new thinking on gender, reproductive technologies and global movements in the 21 st century. Hum Reprod Update. 2015;21:411-26. PMID: 25801630 DOI: 10.1093/humupd/dmv016

Lass A, Chaudary W, Lass G. Correlation between gross domestic product, utilization of in vitro fertilization, and pregnancy success rate across the world. J Med Econ. 2019;22:878-82. PMID: 31012790 DOI: $10.1080 / 13696998.2019 .1609484$

Mascarenhas MN, Flaxman SR, Boerma T, Vanderpoel S, Stevens GA. National, regional, and global trends in infertility prevalence since 1990: a systematic analysis of 277 health surveys. PLoS Med. 2012;9:e1001356. PMID: 23271957 DOI: $10.1371 /$ journal.pmed.1001356

Mills M, Rindfuss RR, McDonald P, te Velde E; ESHRE Reproduction and Society Task Force. Why do people postpone parenthood? Reasons and social policy incentives. Hum Reprod Update. 2011;17:848-60. PMID: 21652599 DOI: $10.1093 /$ humupd/dmr026

Nishi N, Ikeda N, Sugiyama T, Kurotani K, Miyachi M. Simulating the Impact of Long-Term Care Prevention Among Older Japanese People on Healthcare Costs From 2020 to 2040 Using System Dynamics Modeling. Front Public Health. 2020;8:592471. PMID: 33381487 DOI: 10.3389/ fpubh.2020.592471

Per capita GDP data of all countries in the world in 2012. Kuaiyi Finance; 2021. Available at https://www.

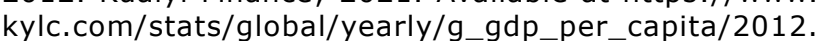
html

Sunderam S, Kissin DM, Crawford SB, Folger SG, Jamieson DJ, Warner L, Barfield WD; Centers for Disease Control and Prevention (CDC). Assisted Reproductive Technology Surveillance - United States, 2012. MMWR Surveill Summ. 2015;64:1-29. PMID: 26633040 DOI: 10.15585/mmwr. ss6411a1

Sunderam S, Kissin DM, Zhang Y, Folger SG, Boulet SL, Warner L, Callaghan WM, Barfield WD. Assisted Reproductive Technology Surveillance - United States, 2016. MMWR Surveill Summ. 2019;68:1-23. PMID: 31022165 DOI: $10.15585 / \mathrm{mmwr} . \mathrm{ss} 6804 \mathrm{a} 1$

Tarín JJ, García-Pérez MA, Cano A. Assisted reproductive technology results: why are live-birth percentages so low? Mol Reprod Dev. 2014;81:568-83. PMID: 24810886 DOI: $10.1002 / \mathrm{mrd} .22340$ 


\begin{tabular}{|c|c|c|c|c|c|c|c|c|c|c|}
\hline $\begin{array}{r}\text { Suppleme } \\
\text { delivery rat }\end{array}$ & $\begin{array}{l}\text { tary Table } \\
s \text { in } 2012 .\end{array}$ & GDP per $c$ & pita o & ontri & and the re & orted c & a abou & ART Cyc & es and & gnan \\
\hline & GDP PER & & IVF & & & ICSI & & & FET & \\
\hline Country & $\begin{array}{c}\text { (10 } \\
\text { thousand } \\
\text { dollars) }\end{array}$ & $\begin{array}{c}\text { IVF } \\
\text { aspirations }\end{array}$ & $\begin{array}{c}\text { IVF- } \\
\text { PR } \\
(\%)\end{array}$ & $\begin{array}{c}\text { IVF- } \\
\text { DR } \\
(\%)\end{array}$ & $\begin{array}{c}\text { ICSI } \\
\text { aspirations }\end{array}$ & $\begin{array}{c}\text { IC- } \\
\text { SI-PR } \\
(\%)\end{array}$ & $\begin{array}{c}\text { IC- } \\
\text { SI-DR } \\
(\%)\end{array}$ & $\begin{array}{c}\text { FET } \\
\text { cycles }\end{array}$ & $\begin{array}{c}\text { FET-PR } \\
(\%)\end{array}$ & $\begin{array}{c}\text { FET- } \\
\text { DR } \\
(\%)\end{array}$ \\
\hline Albania & 0.4247 & 0 & NA & NA & 204 & 41.7 & 33.8 & 39 & 51.3 & 38.5 \\
\hline Argentina & 1.31 & 504 & 35 & 27 & 5515 & 25.1 & 18.4 & 1971 & 27.8 & 20.2 \\
\hline Australia & 6.8 & NA & NA & NA & NA & NA & NA & 20181 & 29.1 & 22.5 \\
\hline Austria & 4.86 & 920 & 34.7 & NA & 4919 & 31.3 & NA & 955 & 34.6 & 13.3 \\
\hline Belarus & 4.16 & 1229 & 39.8 & 27.3 & 659 & 46.7 & 34.4 & 107 & 26.2 & 13.1 \\
\hline Belgium & 4.47 & 3996 & 28.7 & 21.1 & 9277 & 25.5 & 18.4 & 7996 & 26.4 & 18.9 \\
\hline Benin & 0.08 & 9 & 33.3 & 33.3 & 92 & 37 & 28.3 & 0 & NA & NA \\
\hline Bolivia & 0.26 & 148 & 36.7 & 25.9 & 62 & 36.1 & 27.9 & 14 & 35.7 & 28.6 \\
\hline Brazil & 1.24 & 1070 & 32.4 & 28.4 & 13937 & 31 & 25.2 & 3895 & 32.3 & 25.3 \\
\hline Bulgaria & 0.74 & 593 & 27.3 & 17.9 & 587 & 21.4 & 15.6 & 573 & 33.5 & 26.5 \\
\hline Cameroon & 0.14 & 204 & 17.2 & 14.7 & 202 & 21.8 & 16.3 & NA & NA & NA \\
\hline Canada & 5.27 & 4552 & 33.4 & 24.5 & 10494 & 35.8 & 27.1 & 7028 & 32.4 & 23.7 \\
\hline Chile & 1.54 & 131 & 44.3 & 32.8 & 1321 & 35 & 27.2 & 470 & 35.7 & 25.7 \\
\hline Colombia & 0.81 & 293 & 35 & 27.5 & 622 & 34.2 & 26.5 & 165 & 23 & 18.2 \\
\hline Croatia & 1.32 & 1811 & 26.7 & 7.2 & 2736 & 24.2 & 10.5 & 131 & 23.7 & 10.7 \\
\hline $\begin{array}{l}\text { Czech } \\
\text { Republic }\end{array}$ & 1.97 & 1739 & 17.8 & 14.2 & 10147 & 33.4 & 24.4 & 5789 & 31.7 & 20.1 \\
\hline Denmark & 5.85 & 5970 & 25 & 22.1 & 5278 & 25.2 & 22.7 & 2566 & 22.6 & 19.5 \\
\hline $\begin{array}{l}\text { Dominican } \\
\text { Republic }\end{array}$ & 0.68 & 42 & 9.8 & 7.3 & 35 & 22.9 & 20 & 3 & NA & NA \\
\hline Ecuador & 0.57 & 216 & 43.7 & 37.9 & 324 & 29 & 21.8 & 121 & 34.7 & 28.9 \\
\hline Egypt & 0.32 & 0 & NA & NA & 7848 & 35 & 17.9 & 1819 & 23.1 & 10.2 \\
\hline Estonia & 2.32 & 606 & 27.7 & 22.8 & 1188 & 28.7 & 23.5 & 634 & 18.8 & 12 \\
\hline Finland & 4.77 & 2475 & 28.6 & 22.1 & 2143 & 25.7 & 20.8 & 3319 & 24.3 & 18 \\
\hline France & 4.09 & 20995 & 23.8 & 19.2 & 39079 & 24 & 19.6 & 21296 & 18.7 & 14.7 \\
\hline Germany & 4.39 & 12047 & 27.2 & 17.8 & 39911 & 26.6 & 18.1 & 18466 & 21 & 13.2 \\
\hline Ghana & 0.16 & 18 & 66.7 & 55.6 & 9 & 75 & 75 & 0 & NA & NA \\
\hline Greece & 2.22 & 1329 & 32.8 & 15.7 & 5343 & 32.2 & 17.2 & 1079 & 35 & 17.1 \\
\hline Guatemala & 0.34 & 38 & 27 & 18.9 & 62 & 29.5 & 19.7 & 7 & 42.9 & 14.3 \\
\hline Hungary & 1.29 & 920 & 34.5 & NA & 3502 & 31.7 & NA & 398 & 31.7 & NA \\
\hline Iceland & 4.59 & 199 & 25.6 & 18.1 & 206 & 22.8 & 19.9 & 186 & 19.9 & 15.1 \\
\hline India & 0.14 & NA & NA & NA & NA & NA & NA & 4959 & 38 & 33.8 \\
\hline Indonesia & 0.37 & 519 & NA & NA & 2635 & 40.4 & 40.4 & 427 & 24.1 & 24.1 \\
\hline Ireland & 4.89 & 904 & 34.4 & 24.7 & 922 & 32 & 24.4 & 670 & 24.9 & 15.1 \\
\hline Israel & 3.25 & NA & NA & NA & NA & NA & NA & 9044 & 24.7 & 15.7 \\
\hline Italy & 3.51 & 7397 & 23.9 & 15.3 & 42690 & 21.8 & 14 & 5496 & 22.4 & 14.4 \\
\hline Japan & 4.86 & 77370 & 11.7 & 8 & 122962 & 9.8 & 6.6 & 116023 & 33.7 & 23 \\
\hline Kazakhstan & 2.08 & 1188 & 37.5 & 24.7 & 1059 & 41.8 & 28.3 & 436 & 36.5 & 24.3 \\
\hline Lebanon & 0.8 & 3 & 33.3 & 33.3 & 945 & 43.9 & 38.3 & 17 & 11.8 & 5.9 \\
\hline Lithuania & 1.43 & 103 & 41.7 & 32 & 46 & 32.6 & 21.7 & 24 & 33.3 & 20.8 \\
\hline Mali & 0.08 & 53 & 52.1 & 52.1 & 101 & 54.8 & 53.8 & 23 & NA & NA \\
\hline Mexico & 1.02 & 1222 & 41.4 & 32.9 & 2017 & 32.4 & 26.4 & 757 & 27.3 & 22.1 \\
\hline Moldova & 0.3 & 429 & 36.1 & 32.6 & 667 & 38.8 & 36 & 43 & 23.3 & 18.6 \\
\hline Montenegro & 0.66 & 2 & 50 & 50 & 504 & 29.4 & 24.8 & 14 & 21.4 & 21.4 \\
\hline
\end{tabular}


Continued Supplementary Table 1.

\begin{tabular}{|c|c|c|c|c|c|c|c|c|c|c|}
\hline Morocco & 0.29 & 126 & 27 & NA & 433 & 29.8 & NA & NA & NA & NA \\
\hline Netherlands & 5.01 & 7139 & 28.2 & 19.4 & 8122 & 29.8 & 21.8 & 8063 & 23.2 & 15.7 \\
\hline $\begin{array}{l}\text { New } \\
\text { Zealand }\end{array}$ & 4 & NA & NA & NA & NA & NA & NA & 1572 & 34 & 25.1 \\
\hline Nicaragua & 0.18 & 46 & 47.8 & 39.1 & 41 & 36.6 & 31.7 & NA & NA & NA \\
\hline Nigeria & 0.27 & 272 & 40.1 & 18.2 & 1121 & 27.1 & 16.4 & 54 & 27.8 & 24.1 \\
\hline Norway & 10.15 & 3131 & 29.3 & 23.6 & 2925 & 28 & 23.2 & 2208 & 23.2 & 18.4 \\
\hline Panama & 1.07 & 7 & 50 & 50 & 192 & 40.1 & 28.5 & 72 & 43.1 & 30.6 \\
\hline Peru & 0.65 & 298 & 28.6 & 23.5 & 875 & 22.9 & 17.7 & 231 & 51.5 & 42 \\
\hline Poland & 1.31 & 450 & 30 & 20.9 & 10017 & 34.7 & 26.4 & 4736 & 27.8 & 19.6 \\
\hline Portugal & 2.06 & 1838 & 34.3 & 26.5 & 3385 & 28.4 & 21.8 & 1011 & 23.1 & 16 \\
\hline Romania & 0.85 & 627 & 40 & 31.9 & 908 & 31.6 & 25.3 & 333 & 21 & 12 \\
\hline Russia & 1.54 & 21144 & 34.1 & 24.3 & 25062 & 30.1 & 21.2 & 9880 & 32.1 & 18.7 \\
\hline $\begin{array}{l}\text { Saudi } \\
\text { Arabia }\end{array}$ & 2.52 & 0 & NA & NA & 1670 & 33 & 29.7 & 68 & 57.4 & 30.9 \\
\hline Serbia & 0.6 & 510 & 35.3 & 27.1 & 1386 & 34.6 & 28.6 & NA & NA & NA \\
\hline Slovenia & 2.26 & 1231 & 31.8 & 25.3 & 2278 & 25.5 & 20.5 & 801 & 25.5 & 20.3 \\
\hline $\begin{array}{l}\text { South } \\
\text { Africa }\end{array}$ & 0.75 & 994 & 28.3 & NA & 2423 & 27.9 & NA & 541 & 29.6 & NA \\
\hline $\begin{array}{l}\text { South } \\
\text { Korea }\end{array}$ & 2.55 & 10980 & 34.6 & 12.2 & 21280 & 29.6 & 12.2 & 10441 & 36.1 & 14.6 \\
\hline Spain & 2.83 & 3277 & 33.5 & 19.4 & 27926 & 31 & 18.1 & 10744 & 31.7 & 17.9 \\
\hline Sweden & 5.8 & 5437 & 30.8 & 24.7 & 5695 & 30.6 & 24.9 & 5244 & 28.7 & 22.9 \\
\hline Switzerland & 8.35 & 710 & 25.8 & 20 & 4126 & 22.6 & 16.6 & 3697 & 22.9 & 17 \\
\hline Togo & 0.06 & 20 & 15 & 10 & 53 & 24 & 22 & 5 & 0 & 0 \\
\hline Tunisia & 0.42 & 378 & 36 & 33.1 & 3581 & 33.6 & 29.4 & 757 & 27.3 & 21.1 \\
\hline UK & 4.25 & 18853 & 31 & 27 & 24299 & 31.8 & 27.8 & 10253 & 27.4 & 23.8 \\
\hline Ukraine & 0.39 & 3383 & 41.6 & 29.9 & 5116 & 37.4 & 29.9 & 2173 & 36.3 & 25.1 \\
\hline Uruguay & 1.52 & 20 & 50 & 44.4 & 233 & 31.6 & 26.8 & 56 & 30.4 & 19.6 \\
\hline USA & 5.16 & 20233 & 42.5 & 34.2 & 58397 & 41.2 & 33.3 & 34197 & 48.1 & 38.1 \\
\hline Venezuela & 1.3 & 369 & 40 & 32.6 & 184 & 33.7 & 23.7 & 118 & 41.5 & 32.2 \\
\hline
\end{tabular}


Supplementary Table 2. GDP per capita of USA states and the reported data about ART cycles and pregnant/delivery rate in 2012.

\begin{tabular}{|c|c|c|c|c|}
\hline States & $\begin{array}{c}\text { GDP PER CAPITA } \\
\text { (10 thousand dollars) }\end{array}$ & ART cycles & $\begin{array}{c}\text { PR (\%) } \\
\text { Pregnancies/ART }\end{array}$ & $\begin{array}{c}\text { DR (\%) } \\
\text { Pregnancies/ART }\end{array}$ \\
\hline Alabama & 3.26 & 873 & 40.8 & 34.1 \\
\hline Alaska & 6.12 & 207 & 34.8 & 27.5 \\
\hline Arizona & 3.52 & 2261 & 39.2 & 30.9 \\
\hline Arkansas & 3.18 & 492 & 38.4 & 32.5 \\
\hline California & 4.6 & 20241 & 41.9 & 33.6 \\
\hline Colorado & 4.62 & 1705 & 58.8 & 49.6 \\
\hline Connecticut & 5.49 & 3148 & 35.7 & 28.4 \\
\hline Delaware & 6.12 & 585 & 39.0 & 32.5 \\
\hline District of Columbia & 14.6 & 1228 & 32.4 & 25.1 \\
\hline Florida & 3.48 & 6785 & 38.7 & 31.5 \\
\hline Georgia & 3.77 & 3176 & 45.2 & 37.2 \\
\hline Hawaii & 4.44 & 886 & 40.1 & 32.5 \\
\hline Idaho & 3.19 & 399 & 52.6 & 44.9 \\
\hline Illinois & 4.62 & 10449 & 36.3 & 29.6 \\
\hline Indiana & 3.91 & 1729 & 37.2 & 32.0 \\
\hline Iowa & 4.22 & 1225 & 48.8 & 39.2 \\
\hline Kansas & 4.11 & 689 & 45.3 & 39.2 \\
\hline Kentucky & 3.35 & 1172 & 41.0 & 34.9 \\
\hline Louisiana & 4.31 & 1013 & 47.1 & 30.9 \\
\hline Maine & 3.46 & 506 & 27.5 & 21.3 \\
\hline Maryland & 4.67 & 5770 & 39.8 & 31.7 \\
\hline Massachusetts & 5.32 & 9754 & 35.5 & 28.6 \\
\hline Michigan & 3.53 & 3532 & 38.8 & 31.3 \\
\hline Minnesota & 4.7 & 2130 & 47.7 & 40.4 \\
\hline Mississippi & 2.89 & 461 & 37.1 & 31.5 \\
\hline Missouri & 3.68 & 1847 & 41.2 & 34.1 \\
\hline Montana & 3.32 & 210 & 47.1 & 38.6 \\
\hline Nebraska & 4.49 & 649 & 37.3 & 30.7 \\
\hline Nevada & 4.1 & 914 & 45.2 & 37.0 \\
\hline New Hampshire & 4.3 & 817 & 37.7 & 30.5 \\
\hline New Jersey & 4.94 & 8590 & 41.9 & 34.1 \\
\hline New Mexico & 3.39 & 359 & 42.6 & 35.9 \\
\hline New York & 5.31 & 19618 & 34.0 & 27.0 \\
\hline North Carolina & 4.03 & 3219 & 44.2 & 36.1 \\
\hline North Dakota & 5.53 & 239 & 43.5 & 36.8 \\
\hline Ohio & 3.77 & 3601 & 42.0 & 35.0 \\
\hline Oklahoma & 3.63 & 759 & 47.8 & 39.3 \\
\hline Oregon & 4.81 & 1104 & 49.6 & 43.8 \\
\hline Pennsylvania & 4.01 & 5984 & 37.1 & 30.0 \\
\hline Rhode Island & 4.17 & 699 & 34.6 & 28.2 \\
\hline South Carolina & 3.19 & 791 & 44.8 & 36.4 \\
\hline South Dakota & 4.32 & 257 & 43.2 & 35.8 \\
\hline Tennessee & 3.73 & 1234 & 40.8 & 34.0 \\
\hline Texas & 4.65 & 10281 & 45.5 & 37.8 \\
\hline Utah & 3.92 & 1398 & 49.1 & 40.9 \\
\hline
\end{tabular}


Continued Supplementary Table 2.

\begin{tabular}{|l|c|c|c|c|}
\hline Vermont & 3.82 & 220 & 35.5 & 30.5 \\
\hline Virginia & 4.71 & 5642 & 36.0 & 28.4 \\
\hline Washington & 4.71 & 3301 & 41.2 & 34.5 \\
\hline West Virginia & 3.04 & 263 & 40.3 & 37.3 \\
\hline Wisconsin & 3.93 & 1657 & 43.9 & 37.3 \\
\hline Wyoming & 5.43 & 88 & 54.5 & 45.5 \\
\hline
\end{tabular}

